\title{
TRENDS IN BIOENGINEERING PATENTS GRANTED 2000 - 2019
}

\author{
Judith E. Pasek \\ University of Wyoming, Laramie, WY, USA
}

Corresponding Author: Judith E. Pasek

University of Wyoming Libraries, Dept. 3334, 1000 E. University Ave., Laramie, WY, 82071-2000

Email: jpasek@uwyo.edu

https://doi.org/10.34107/BiomedSciInstrum.57.0461

\begin{abstract}
Patent documents contain a wealth of technical information on inventions, often unavailable elsewhere. They are likely underutilized as sources of information about trends in fields of development. Querying patent databases can be challenging, given the inadequacy of keywords and the complex nature of patent classification systems. A collection of Cooperative Patent Classification (CPC) main codes were identified that likely relate to patents in bioengineering and biomedical engineering. These codes were used in queries of the free patent search engine that is available from a Lens.org database. Results were filtered for applications or granted patents by patent families to identify trends in inventions within the field from 2000 to 2019. A patent family represents the collection of documents relating to a single invention given that applications are frequently filed in multiple countries. Although patent applications and unique inventions remained steady, the annual number of patents granted has increased from 2000 to 2016. A decline in numbers of granted patents since 2016 is indicative of the lag time of several years between application filing and a determination of patent status. Applicants with high productivity in obtaining granted patents include large international companies as well as some large universities.
\end{abstract}

Keywords: patent trends, innovations, intellectual property, biomedical engineering, Rocky Mountain Bioengineering Symposium

\section{INTRODUCTION}

Patent documents are a rich source of technical information on inventions that might not be published elsewhere. Publishing research and development information ahead of patent approval can jeopardize the granting of intellectual property protections. For commercial entities, unlike academic institutions, there may be little incentive to publish scientific reports of inventions after a patent is granted. Estimates of the magnitude of new technology that is not disclosed in non-patent literature are $70-80 \%$ or more [1]. As a consequence, important information about technological innovations may be missed if literature searching is limited to conventional publication sources. The legal purposes of patent documents as well as the challenging nature of patent searching may be hindrances to greater use as scientific information sources.

Keyword searching, a common approach used for locating non-patent literature, typically produces incomplete results in patent databases. Descriptions of new inventions are often cryptic, and establishment of standardized terminology tends to lag behind technology developments. Comprehensive patent searching using keywords therefore may require construction of lengthy lists of related terms, iterative queries and de-duplication, and time-consuming examination of results, or use of complex text-mining techniques. Keyword matching is also limited when full text searching is unavailable.

Classification searching can improve retrieval of relevant patent records. However, several patent classification systems exist, and codes are often added or discontinued as technology advances. The Cooperative Patent Classification (CPC) system is an enhancement of the International Patent Classification (IPC) system, and replaced the United States Patent Classification (USPC) system and the European Classification (ECLA) system. The CPC is now widely used in addition to the IPC 